\title{
TIPOLOGI PERUBAHAN TUTUPAN HUTAN DI KABUPATEN KUBU RAYA KALIMANTAN BARAT
}

\author{
(Typology of Forest Cover Change in Kubu Raya Village, West Kalimantan) \\ Hanifah Ikhsani ${ }^{1}$ \\ ${ }^{1)}$ Staff Pengajar Fakultas Kehutanan Universitas Lancang Kuning \\ Jln. Yos Sudarso Km. 8 Rumbai Pekanbaru Riau \\ Email: hanifahikht2@gmail.com
}

Diterima: 26 April 2019, Direvisi: 14 Juli 2019, Disetujui: 15 Juli 2019

DOI: https://doi.org/10.31849/forestra

\begin{abstract}
Forest cover changes were influenced by many factors, some of which were biophysical characteristics, socio-economic conditions, and community cultural. The behavior of forest cover changes in each of Indonesia's regions varied. The establishment of village typologies to categorize village administrative areas becomes important to see the driving factors that trigger forest change in each typology. The objective of this study was to develop the village typology of forest cover change in each village in Kubu Raya Regency, West Kalimantan. The development of village typology was done by applying the clustering approach with standardized euclidean distances. Based on the proportion of forest in 2015, the study found that there are two village typologies within the study area with $81 \%$ OA.
\end{abstract}

Keywords: euclidean distance, kubu raya, typologies

Perubahan tutupan hutan dipengaruhi oleh berbagai faktor, diantaranya adalah faktor biofisik, sosial ekonomi dan sosial budaya masyarakat. Perubahan tutuan hutan di berbagai wilayah di Indonesia bervariasi. Pembangunan tipologi sangat penting karena dapat memperlihatkan kelompok desa satu dan lainnya yang memiliki tipe perubahan hutan yang sama serta dapat membantu mengetahui faktor pendrong terjadinya perubahan hutan di Kabupaten Kubu Raya, Kalimantan Barat. Penelitian ini bertujuan untuk mengidentifikasi tipologi desa perubahan tutupan hutan di Kabupaten Kubu Raya, Kalimantan Barat. Pembangunan tipologi menggunakan pengelompokkan berdasarkan jarak euclidean terstandarisasi. Berdasarkan proporsi hutan tahun 2015, penelitian ini menemukan 2 tipologi perubahan tutupan hutan di Kabupaten Kubu Raya dengan akurasi keseluruhan $81 \%$. Tipologi perubahan tutupan hutan untuk tingkat desa di Kabupaten Kubu Raya dapat dikelompokkan menjadi 2 kelas tipologi dengan nilai OA sebesar $81 \%$. T1 mencakup 56 desa dengan laju perubahan tutupan hutan yang rendah (5001.8 ha per tahun). Tipologi 2 merupakan tipologi yang memiliki proporsi hutan dan laju perubahan hutan yang tinggi (8050.6 ha per tahun) sebanyak 34 desa

Kata kunci : jarak euclidean, kubu raya, tipologi 


\section{PENDAHULUAN}

Indonesia memiliki hutan yang bernilai tinggi bagi ekosistem dunia. Akan tetapi, keberadaannya semakin terdesak akibat kebutuhan lahan untuk penggunaan lainnya yang merupakan implikasi dari pertumbuhan ekonomi dan pertambahan penduduk. Pada tiga dekade terakhir, luas hutan semakin menurun di wilayah-wilayah tertentu bahkan dengan laju perubahan tutupan hutan yang mengkhawatirkan (FWI 2014; KLHK 2017. Perubahan tutupan hutan dapat berupa perubahan tutupan hutan menjadi tutupan non hutan atau perubahan tutupan non hutan menjadi tutupan hutan. Pada satu sisi, perubahan tutupan hutan tersebut dapat menyebabkan terjadinya perubahan iklim, sedangkan disisi lain pembukaan lahan kurang produktif untuk keperluan pembangunan sangat diperlukan (Siswoko 2008; IPCC 2013).

Pulau Kalimantan adalah salah satu pulau yang sering menjadi perhatian nasional dan dunia karena tingkat perubahan hutannya yang sangat tinggi. Salah satu wilayah yang mengalami perubahan tutupan hutan yang tinggi di Provinsi Kalimantan Barat adalah Kabupaten Kubu Raya (Curran et al. 2004). Perubahan tutupan hutan yang terdapat di Kabupaten Kubu Raya adalah perubahan tutupan hutan menjadi non hutan, seperti perubahan tutupan hutan menjadi perkebunan, semak belukar rawa, pertanian lahan kering campuran, tanah terbuka, sawah, tambak, pemukiman dan lainnya. Jenis perubahan tutupan lahan tersebut dapat digunakan sebagai indikator penyebab terjadinya perubahan tutupan hutan di setiap wilayah perubahan.

Penelitian perubahan penutupan hutan ini menjadi sangat penting mengingat penyusunan perencanaan wilayah sudah ada pada tingkat wilayah kabupaten. Sejak diundangkannya undang-undang otonomi daerah No. 22 Tahun 1999, sebagaimana otonomi daerah sejak tahun 2000, kajian tentang pola dan karakter perubahan tutupan hutan di Indonesia masih sangat sedikit, dan kebanyakan pada tingkat provinsi hingga pulau (Albar et al. 2015; Sulistyono et al. 2015; Wijaya et al. 2015). Pada studi ini, kajian spasial perubahan tutupan hutan dilakukan pada tingkat kabupaten dengan satuan pengamatan terkecilnya adalah desa.

Berdasarkan berbagai kajian yang dilakukan di beberapa tempat seperti di Sumatera (Sulistyono et al. 2015; Albar et al. 2015; Wijaya et al. 2015), perilaku dan karakter di setiap wilayah sangat bervariasi berdasarkan kondisi biofisik, ekonomi, sosial, budaya, dan politik. Oleh karena itu, tipologi dilakukan untuk mengetahui karakteristik desa terhadap terjadinya perubahan tutupan hutan pada tingkat administrasi desa.

Tipologi dapat mempermudah mengetahui faktor pemicu dan pola spasial terjadinya perubahan tutupan hutan (Pang et al. 2013; Sulistiyono et al. 2015). Hal tersebut mempermudah untuk melihat faktor pendorong yang menjadi pemicu perubahan tutupan hutan yang unik pada masingmasing tipologi. Faktor pendorong yang menjadi pemicu terjadinya perubahan tutupan hutan di level desa juga berbedabeda. Perubahan tutupan hutan diperkirakan tidak terlepas dari pengaruh kondisi sosial ekonomi, budaya, dan kelembagaan di setiap desa. Oleh karena itu, faktor tersebut dapat memengaruhi faktor pendorong perubahan tutupan hutan.

Penelitian ini bertujuan untuk mengidentifikasi tipologi desa perubahan tutupan hutan di Kabupaten Kubu Raya, Kalimantan Barat. 


\section{METODE PENELITIAN}

Penelitian ini dilakukan pada bulan September tahun 2017 sampai bulan April tahun 2018. Penelitian ini dilaksanakan di Kabupaten Kubu Raya, Kalimantan Barat. Secara geografis, Kabupaten Kubu Raya terletak pada koordinat $108^{\circ} 35^{\prime}-109^{\circ} 58^{\prime} \mathrm{BT}$ dan $00^{\circ} 44^{\prime} \mathrm{LU}-10^{\circ} 01^{\prime} \mathrm{LS}$. Analisis dan pengolahan data dilakukan di Laboratorium Remote Sensing dan Geographic Information System (GIS) Departemen Manajemen Hutan, Fakultas Kehutanan, Institut Pertanian Bogor. Kabupaten Kubu Raya, Kalimantan Barat terdiri atas 9 kecamatan, 118 desa, 447 dusun, 782 RW, dan 3089 RT (BPS 2016). Penelitian ini menggunakan 90 desa, karena desa-desa tersebut merupakan desa yang pada tahun 2000 masih memiliki hutan alam.

Alat yang digunakan pada penelitian ini adalah Global Positioning System (GPS), kamera, tally sheet, dan alat tulis. Hardware yang digunakan, yaitu seperangkat komputer dengan software: ArcGIS 10.1, Erdas imagine 9.1 dan Minitab 17. Data yang digunakan adalah citra satelit Landsat TM multitemporal perekaman tahun 2011 dan 2015 yang berasal dari United States Geological Survey (USGS), data penutupan lahan tahun 2000 dan 2015 yang berasal dari Kementerian Lingkungan Hidup dan Kehutanan (KLHK), data statistik Kecamatan dalam Angka di Kabupaten Kubu Raya, Kalimantan Barat tahun 2009 dan 2016, data administrasi yang berasal dari Badan Informasi Geospasial (BIG), dan data ground check lapangan.

\section{Pemilihan Peubah Tipologi}

Pemilihan peubah menggunakan analisis korelasi untuk mengetahui keeratan dan arah hubungan antara dua peubah yang digunakan sebagai peubah untuk membuat tipologi (Albar et al. 2015; Lastini 2012; Sulistiyono et al. 2015). Penelitian ini mengeluarkan perubahan penutupan lahan hutan tanaman pada perhitungan perubahan tutupan hutan. Hal ini dilakukan untuk mempermudah analisis laju perubahan tutupan hutan di Kabupaten Kubu Raya, Kalimantan Barat.

Penelitian ini menggunakan peubahpeubah berdasarkan kondisi biofisik, sosial, dan ekonomi masyarakat yang tersedia pada level desa yang diperkirakan akan memengaruhi perubahan tutupan hutan. Peubah yang digunakan merupakan peubah biofisik, sosial, dan ekonomi tahun 20002015. Peubah biofisik, sosial, dan ekonomi (X) dan peubah laju perubahan tutupan hutan (Y) untuk pembuatan tipologi dapat dilihat pada Tabel 1. Peubah persen laju perubahan tutupan hutan didapatkan dari laju perubahan tutupan hutan tahun 20002015 dibagi dengan luas hutan awal (luas hutan tahun 2000). Korelasi antar peubah biofisik, sosial, dan ekonomi dengan kriteria r>0.65 digunakan salah satu peubah yang tertinggi untuk dikorelasi dengan peubah laju perubahan tutupan hutan dengan kriteria $r>0.25$ (Sarwono 2006).

\section{Tabel 1. Peubah Pembuatan Tipologi}

\begin{tabular}{|l|c|}
\hline \multicolumn{1}{|c|}{ Peubah } & Notasi Peubah \\
\hline $\begin{array}{l}\text { Proporsi hutan tahun 2000 } \\
\text { (ha) }\end{array}$ & $\mathrm{X}_{1}$ \\
\hline $\begin{array}{l}\text { Proporsi hutan tahun 2015 } \\
\text { (ha) }\end{array}$ & $\mathrm{X}_{2}$ \\
\hline $\begin{array}{l}\text { Jumlah penduduk tahun } \\
\text { 2000-2015 (Jiwa) }\end{array}$ & $\mathrm{X}_{3}$ \\
\hline $\begin{array}{l}\text { Laju penduduk tahun } \\
\text { 2000-2015 (Jiwa per } \\
\text { tahun) }\end{array}$ & $\mathrm{X}_{4}$ \\
\hline Laju jumlah sekolah tahun & $\mathrm{X}_{5}$ \\
\hline
\end{tabular}


2000-2015 (Unit per

tahun)

\begin{tabular}{|l|c|}
\hline \multicolumn{1}{|c|}{ Peubah } & Notasi Peubah \\
\hline $\begin{array}{l}\text { Jumlah sekolah tahun } \\
\text { 2000-2015 (Unit) }\end{array}$ & $\mathrm{X}_{6}$ \\
\hline $\begin{array}{l}\text { Laju jumlah murid tahun } \\
\text { 2000-2015 (Jiwa per } \\
\text { tahun) }\end{array}$ & $\mathrm{X}_{7}$ \\
\hline $\begin{array}{l}\text { Jumlah murid tahun 2000- } \\
\text { 2015 (Jiwa) }\end{array}$ & $\mathrm{X}_{8}$ \\
\hline $\begin{array}{l}\text { Laju jumlah guru tahun } \\
\text { 2000-2015 (Jiwa per } \\
\text { tahun) }\end{array}$ & $\mathrm{X}_{9}$ \\
\hline $\begin{array}{l}\text { Jumlah guru tahun 2000- } \\
\text { 2015 (Jiwa) }\end{array}$ & $\mathrm{X}_{10}$ \\
\hline $\begin{array}{l}\text { Laju jumlah dokter tahun } \\
\text { 2000-2015 (Jiwa per } \\
\text { tahun) }\end{array}$ & $\mathrm{X}_{11}$ \\
\hline $\begin{array}{l}\text { Jumlah dokter tahun 2000- } \\
\text { 2015 (Jiwa) }\end{array}$ & $\mathrm{X}_{12}$ \\
\hline $\begin{array}{l}\text { Laju jumlah puskesmas } \\
\text { tahun 2000-2015 (Unit per } \\
\text { tahun) }\end{array}$ & $\mathrm{X}_{13}$ \\
\hline $\begin{array}{l}\text { Jumlah puskesmas tahun } \\
\text { 2000-2015 (Unit) }\end{array}$ & $\mathrm{X}_{14}$ \\
\hline $\begin{array}{l}\text { Laju perubahan tutupan } \\
\text { hutan (ha per tahun) }\end{array}$ & $\mathrm{Y}$ \\
\hline
\end{tabular}

\section{Pembangunan Tipologi}

Pembangunan tipologi desa dilakukan menggunakan pendekatan klastering dengan jarak Euclidean yang terstandardisasi menggunakan dendrogram (Valbuena et al. 2008; Lastini 2012). Pengelompokan yang digunakan pada penelitian ini menggunakan average linkage method atau metode dengan prinsip jarak rata-rata (Jaya 2010; Wijaya et al. 2015). Tipologi dibangun berdasarkan peubah terpilih pada analisis korelasi yaitu $\mathrm{X}_{2}$ (proporsi hutan tahun 2015).

Kelas tipologi yang terbentuk dihubungkan dengan perubahan tutupan hutan dengan melakukan uji akurasi. Kelas tipologi terpilih yang dilanjutkan pada pembuatan model adalah kelas tipologi dengan OA tertinggi. Secara umum, persamaan OA dirumuskan sebagai berikut:

$$
O A=\frac{\sum_{i=1}^{r} X_{i i}}{N} 100 \%
$$

Keterangan:

OA : Nilai akurasi rata-rata umum

$X_{i i} \quad$ : Kelas tingkat keberhasilan yang sama antara peubah model dan validasi

$X_{i k} \quad$ : Nilai peubah ke-i dari klaster k

\section{HASIL DAN PEMBAHASAN}

Pembuatan tipologi didahului dengan melakukan uji korelasi peubah biofisik dan sosial ekonomi untuk menghindari kolinearitas antar peubah. Berdasarkan hasil analisis korelasi, diketahui bahwa ada dua faktor pendorong yang sangat erat kaitannya dengan proporsi hutan, yaitu proporsi hutan pada tahun $2000\left(\mathrm{X}_{1}\right)$ dan proporsi hutan pada tahun $2015\left(\mathrm{X}_{2}\right)$. Akan tetapi, antara $\mathrm{X}_{1}$ dan $\mathrm{X}_{2}$ memiliki korelasi yang besar, yaitu 0.7 , pembuatan tipologi menggunakan salah satu dari peubah, yaitu proporsi hutan pada tahun $2015\left(\mathrm{X}_{2}\right)$. Proporsi hutan merupakan persentase luas hutan di desa tersebut.

Tabel 2. Hasil Uji Akurasi Pengelompokan Tipologi Desa

\begin{tabular}{cc}
\hline Jumlah Kelas Dendrogram & OA $(\boldsymbol{\%})$ \\
\hline 4 Kelas & 48.9 \\
3 Kelas & 62.2 \\
2 Kelas & 81.1 \\
\hline
\end{tabular}

Berdasarkan Tabel 2, tipologi yang terbentuk di Kabupaten Kubu Raya adalah sebanyak 2 kelas tipologi, yaitu tipologi 1 (T1) dan tipologi 2 (T2). Tipologi terpilih merupakan tipologi dengan nilai akurasi 
terbesar, yaitu tipologi 2 kelas dengan OA sebesar $81.1 \%$. Tipologi dengan akurasi yang tinggi digunakan untuk mengakuratkan pengelompokan tipologi (Conrad et al. 2011; Albuquerque et al. 2016). Dendrogram menunjukkan bahwa jumlah desa yang termasuk pada $\mathrm{T} 1$ adalah 56 desa dan dan T2 adalah 34 desa (Gambar 1).

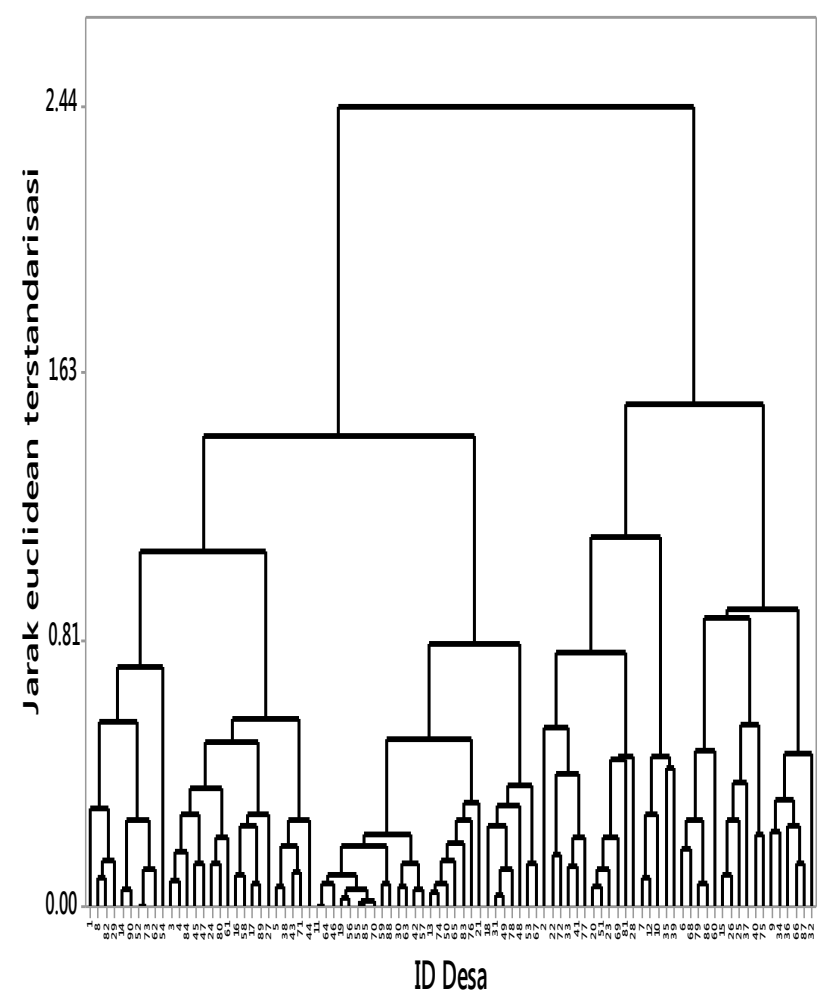

Gambar 1. Dendrogram Dengan Peubah Proporsi Hutan Tahun 2015 Menggunakan Average Linkage Method

Peta sebaran desa yang termasuk T1 dan T2 disajikan pada Gambar 2.

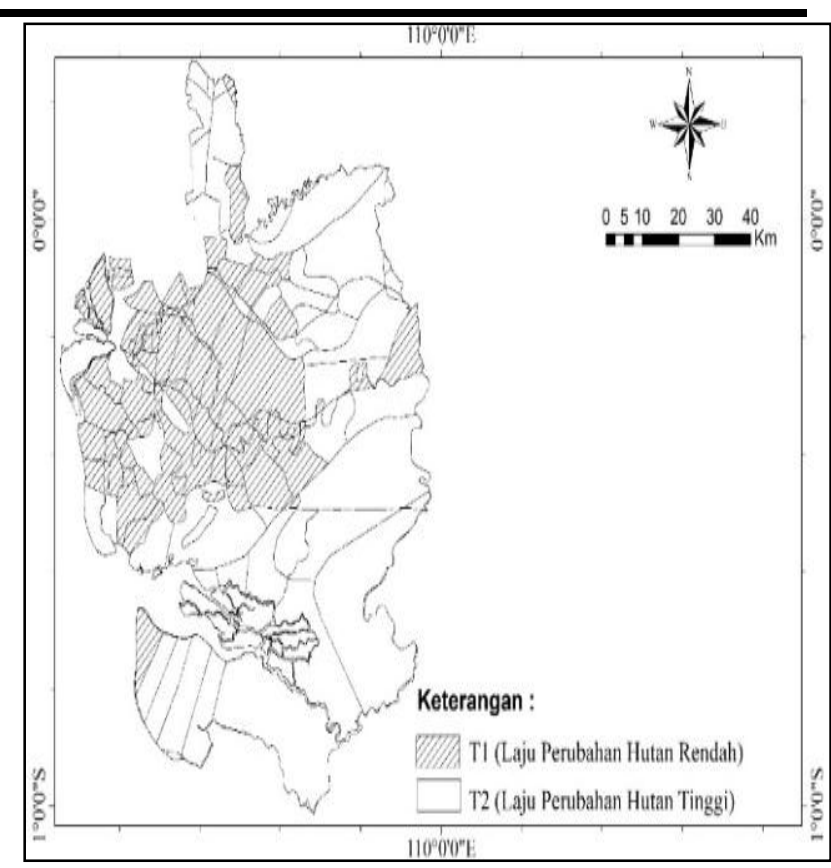

Gambar 2. Sebaran Desa Pada T1 dan T2

Kabupaten Kubu Raya memiliki laju perubahan hutan sebesar 14725.9 ha per tahun atau $2.9 \%$ per tahun. Berdasarkan proporsi hutan, T1 merupakan tipologi yang memiliki proporsi hutan dan laju perubahan hutan yang rendah (36.8\% dan 5001.8 ha per tahun). T2 merupakan tipologi yang memiliki proporsi hutan dan laju perubahan hutan yang tinggi (75.4\% dan 8050.6 ha per tahun). Luas T1 adalah 271168.6 ha dan T2 adalah $542 \quad 631.7$ ha. Hal tersebut menunjukkan penurunan luas hutan pada setiap tipologi terus terjadi dan tidak dapat dihindari. Stok hutan pada suatu wilayah dapat memengaruhi perubahan tutupan hutan.

Wilayah yang memiliki stok hutan yang kecil (T1) memiliki laju perubahan tutupan hutan yang lebih kecil daripada wilayah dengan stok hutan yang besar (T2). Perubahan hutan terbesar pada T1 adalah perubahan hutan menjadi perkebunan dan T2 adalah semak belukar rawa. Pada T1, 
perubahan tutupan hutan telah banyak menjadi tutupan lain, sehingga laju perubahan tutupan hutan menjadi rendah. Pada T2, stok hutan yang lebih tinggi membuat perubahan tutupan hutan menjadi lebih tinggi akibat adanya kepentingan konversi hutan. Hal tersebut terlihat dari perubahan hutan terbesar adalah perubahan hutan menjadi semak belukar rawa. Perubahan menjadi semak belukar rawa diduga sebagian besar merupakan unauthorized forest conversion. Graeub et al. (2016) dan Austin et al. (2017) menyatakan bahwa pembukaan hutan yang tidak terkendali dapat meningkatkan laju perubahan tutupan hutan.

\section{KESIMPULAN}

\section{A. Kesimpulan}

Tipologi perubahan tutupan hutan untuk tingkat desa di Kabupaten Kubu Raya dapat dikelompokkan menjadi 2 kelas tipologi dengan nilai OA sebesar 81\%. T1 mencakup 56 desa dengan laju perubahan tutupan hutan yang rendah (5001.8 ha per tahun). Tipologi 2 merupakan tipologi yang memiliki proporsi hutan dan laju perubahan hutan yang tinggi (8050.6 ha per tahun) sebanyak 34 desa.

\section{B. Saran}

Untuk meningkatkan keakuratan tipologi perubahan tutupan hutan, disarankan adanya penambahan variabel lain seperti faktor kelembagaan dan faktor lainnya.

\section{DAFTAR PUSTAKA}

[BPS] Badan Pusat Statistik. 2016. Kubu Raya Dalam Angka 2016. Jakarta (ID): BPS Kabupaten Kubu Raya.
[FWI] Forest Watch Indonesia. 2014. Potret Keadaan Hutan Indonesia Periode Tahun 2009-2013. Bogor (ID): Forest Watch Indonesia.

Albar, Jaya INS, Saharjo BH, Kuncahyo B. 2016. Spatio-temporal typology of land and forest fire in Sumatra. Indonesian Journal of Electrical Engineering and Computer Science. Vol. 4 No. 1 :83-90.

Albuquerque JP, Herfort B, Eckle M. 2016. The Tasks of the Crowd: A Typology of Tasks in Geographic Information Crowdsourcing and a Case Study in Humanitarian Mapping. Journal of Remote Sensing. Vol. 8 No. 859 :2-22.

Austin KG, Roglich MG, Smith DS, Schwanes AM, Swenson JJ. 2017. Trends I size of tropical deforestation events signal increasing dominance of industrial-scale drivers. Environmental Research Letters. Vol. 12 :1-12.

Conrad C, Colditz RR, Dech S, Klein D, Vlek PLG. 2011. Temporal segmentation of MODIS time series for improving crop classification in Central Asian irrigation systems. International Journal of Remote Sensing. Vol. 32 No. 23 :8763-8778.

Curran LM, Trigg SN, McDonald AK, Astiani D, Hardiono YM, Siregar P, Caniogo I, Kasischke E. 2004. Lowland forest loss in protected areas of Indonesian Borneo. Science. Vol. 303:1000-1002. 
Graeub BE, Chappell MJ, Wittman H, Ledermann S, Kerr RB, GemmillHerren B. 2016. The state of family farms in the world. World Dev Journal. Vol.87:1-15.

[IPCC] Intergovernmental Panel on Climate Change. Climate Change 2013. The Physical Science Basis. Contribution of Working Group I to The Fifth Assessment Report of The Intergovernmental Panel on Climate Change.

Jaya INS. 2010. Analisis Citra Digital: Prespektif Penginderaan Jauh Untuk Pengelolaan Sumber Daya Alam. Fakultas Kehutanan. Bogor (ID): Institut Pertanian Bogor.

Lastini T. 2012. Tipologi Desa Hutan Rakyat: Kasus di Kabupaten Ciamis [Disertasi]. Bogor (ID): Institut Pertanian Bogor.

Pang C, Yu H, He J, Xu J. 2013. Deforestation and Changes in Landscape Patterns from 1979 to 2006 in Suan County, DPR Korea. Forests. Vol. 4:968-983.

Sarwono J. 2006. Metode Penelitian Kuantitatif dan Kualitatif. Yogyakarta: Penerbit Graha Ilmu.

Siswoko BD. 2008. Pembangunan, deforestasi dan perubahan iklim. Jurnal Manajemen Hutan Tropika. Vol. XIV No. 2:88-95.

Sulistiyono N, Jaya INS, Prasetyo LB, Tiryana T. 2015. Spatial model of deforestation in Sumatera islands using typological approach. Jurnal Manajemen Hutan Tropika (Journal of Tropical Forest Management). Vol. 21 No. 3:99-109.

Valbuena D, Verburg PH, Bregt AK. 2008. A method to define a typology for agent-based analysis in regional landuse research. Agriculture, Ecosystems \& Environment. Vol. 128 No. 1 :2736.

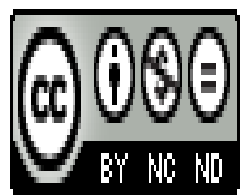

(C) 2019 Wahana Forestra: Jurnal Kehutanan. All rights reserved. This is an open access article distributed under the terms of the BY NC - ND License (https://creativecommons.org/licenses/by-nc-

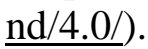

